\title{
PRODUTO SUSTENTÁVEL: UTILIZAÇÃO DE MAPA COGNITIVO PARA DEFINIÇÃO DE REQUISITOS DE SUSTENTABILIDADE NA INDÚTRIA TÊXTIL

\section{José Quadrelli Neto}

Mestre em Engenharia, Instituto Tecnológico de Aeronáutica (ITA) São José dos Campos (SP), Brasil.

\section{Jefferson de Oliveira Gomes (D)}

Professor, ITA - São Jose dos

Campos (SP), Brasil.

\section{Carlos Alberto Schuch Bork}

Professor, Instituto Federal de Educação, Ciência e Tecnologia Sul-Rio-Grandense - Sapucaia do Sul (RS), Brasil.

\section{Endereço para correspondência:}

José Quadrelli Neto-CSB 10, Lotes 2/3, Bloco B, apto. 1.603 Taguatinga SulCEP 72015-605 - Brasília (DF), Brasil-E-mail: jquadrelli@gmail.com

Recebido em: 08/10/2018

Aceito em: $16 / 12 / 2018$

\section{RESUMO}

A demanda por produtos sustentáveis, principalmente devido à pressão da sociedade e à escassez de recursos naturais ou de regulamentações, vem se tornando um mercado atrativo aos consumidores. O governo brasileiro está discutindo a regulamentação sobre compras governamentais sustentáveis com a indústria para conhecer as particularidades de cada setor e estabelecer estratégias de atuação. Esta pesquisa propõe um método para identificar requisitos de sustentabilidade utilizando a ferramenta de mapas cognitivos, na visão do setor industrial têxtil e de confecção, para servir de subsídio nas discussões e negociações governamentais e que possam ser utilizados como referência para esse setor. Como resultado, foram listados para as dimensões ambiental, social, econômica e tecnológica, respectivamente, 16, 19, 11 e 8 requisitos. Com isso, essa pesquisa pode auxiliar o setor em estudo a definir os critérios de sustentabilidade para seus produtos e ainda identificar outros requisitos que devem ser incluídos e priorizados nas discussões sobre compras públicas sustentáveis.

Palavras-chave: produto sustentável; mapa cognitivo; compras públicas.

\section{ABSTRACT}

The demand for sustainable goods, due to the public pressure and the scarcity of resources or regulation, is making the market more attractive to consumers. To understand the specificities of each sector and establish appropriate strategies, the Brazilian government is discussing the regulation of sustainable public procurement with the industry. The present study presents a method to identify sustainable requests by using the cognitive map tool for the textile and clothing industries. Its aim is to support debates and governmental negotiations that could be used as references to the sector. As a result, for the environmental, social, economic and technological dimension, $16,19,11$ and 8 requirements were listed, respectively. Therefore, this study could help the textile and clothing sector define the sustainability criteria for their goods and identify other requests that should be included and prioritized in the debates on sustainable public procurement.

Keywords: sustainable product; cognitive map; public procurement. 


\section{INTRODUÇÃO}

A preocupação com o desenvolvimento de produtos sustentáveis vem crescendo a cada ano. Essa preocupação está relacionada com o aumento das ações do setor produtivo e a maior conscientização do consumidor, tornando-o mais exigente. É fato que grande parte dos avanços alcançados pelo setor produtivo são decorrentes das exigências do mercado e obrigações reguladoras, como normas nacionais e internacionais mais exigentes, no entanto vários setores estão identificando, na sustentabilidade de seus produtos e processos, um diferencial competitivo e uma oportunidade de melhoria no ciclo produtivo (BORK et al., 2016; CENTENERA \& HASAN, 2014; DIEGEL et al., 2010).

O termo desenvolvimento sustentável foi proposto em 1987 pela Comissão Mundial de Meio Ambiente e Desenvolvimento, da Organização das Nações Unidas (ONU), no Relatório de Brundtland, no seguinte contexto: "A humanidade tem que ter a capacidade de fazer com que o desenvolvimento sustentável garanta o atendimento das necessidades do presente sem comprometer a capacidade das gerações futuras satisfazerem suas próprias necessidades" (WCED, 1987).

A Portaria do Ministério do Meio Ambiente (MMA) no 61 , de 16 de maio de 2008, define-o como "práticas de sustentabilidade ambiental a serem observadas pelo Ministério do Meio Ambiente e suas entidades vinculadas quando das compras públicas sustentáveis e dá outras providências" (BRASIL, 2008).

As compras públicas sustentáveis tornam-se um dos principais temas tratados no Plano de Ação para Produção e Consumo Sustentáveis (PPCS), publicado em 2011 pelo MMA, sendo considerada a ferramenta apta para a promoção de mudanças nos padrões de produção e consumo em âmbito nacional, de forma que os torne mais sustentáveis, a partir do uso do poder de compra do governo (CAVALCANTI et al., 2017).

Com isso, o governo brasileiro está dialogando com vários setores industriais, pois as compras governamentais no país movimentam, aproximadamente, $20,2 \%$ do produto interno bruto (PIB), segundo dados de 2014 do Instituto Brasileiro de Geografia e Estatística (IBGE, 2015) referentes à participação do consumo da administração pública. O PIB representa a soma (em valores monetários) de todos os bens e serviços finais produzidos numa determinada região (quer sejam países, estados ou cidades), durante um período determinado (mês, trimestre, ano, etc.), e é um dos indicadores mais utilizados na macroeconomia com o objetivo de quantificar a atividade econômica de uma região. Quanto a compras do Governo Federal em relação apenas aos produtos padronizados (dados de 2014), segundo o Ministério do Planejamento, Desenvolvimento e Gestão, a aquisição de bens e serviços movimentou em torno de $\mathrm{R} \$ \mathbf{7 6 , 5 6}$ bilhões e mobilizou setores importantes da economia, como construção civil, eletroeletrônicos, têxtil, entre outros (GLSSALC, 2008; CAVALCANTI et al., 2017).

O envolvimento do setor industrial nos debates se concretizou no dia 7 de outubro de 2013, quando ocorreu a primeira reunião do Grupo de Trabalho Intersetorial sobre Produção e Consumo Sustentáveis, promovida pelo MMA, cujo objetivo foi debater medidas que estimulem a produção e o consumo sustentáveis no Brasil (TOLENTINO, 2013).

A Confederação Nacional da Indústria (CNI) está participando do processo de construção de uma política de compras públicas sustentável, juntamente com a Associação Brasileira da Indústria Têxtil e de Confecção (ABIT). O diálogo entre o governo e a indústria é importante para o desenvolvimento de políticas públicas eficazes. Desse modo, para garantir uma participação de qualidade do setor industrial, é imperativo que a CNI esteja bem informada sobre os setores industriais da economia brasileira para executar seu papel de órgão máximo de representação da indústria nacional.

Nesse contexto, esta pesquisa propôs um exercício de aplicação de mapas cognitivos para identificar requisitos de sustentabilidade na visão da indústria têxtil e de confecção a fim de servir de subsídio nas discussões governamentais sobre compras públicas sustentáveis e que sejam utilizados como referência para esse setor. Além disso, buscaram-se identificar os requisitos de sustentabilidade e as tendências de priorização dessas condições na visão do setor têxtil e de confecção, além de mapear percepções do setor sobre compras públicas sustentáveis. 


\section{0 processo de desenvolvimento de produtos e a sustentabilidade}

Com o aumento dos desequilíbrios nas relações entre o homem e seu meio, buscam-se novas estratégias de desenvolvimento, com base em uma cultura de sustentabilidade. Por isso, é importante a adoção de um modelo de desenvolvimento que concilie o crescimento econômico, a preservação do meio ambiente e a melhoria das condições sociais (CENTENERA \& HASAN, 2014; DEMAJOROVIC \& MATURANA, 2009; DIEGEL et al., 2010).

A busca pelo desenvolvimento sustentável requer que as empresas, os governos e os indivíduos trabalhem juntos na formulação e no estabelecimento de políticas públicas que auxiliem nessa mudança de padrões de consumo e produção. As empresas necessitam descobrir formas inovadoras para garantir a rentabilidade e, ao mesmo tempo, melhorar o desempenho ambiental e social dos processos de produção e de seus produtos e serviços (UNEP, 2007; VAN WEENEN, 1995).

Diante disso, é preciso que as empresas refaçam suas estratégias produtivas e os pesquisadores se empenhem no desenvolvimento de tecnologias inovadoras e que aproveitem os recursos de forma sustentável (BORK et al., 2016).

O termo sustentabilidade apresenta três dimensões: ambiental, econômica e social. Na área dos negócios, o termo triple bottom line foi elaborado para explicar a importância de alcançar a sustentabilidade. Isso implica que a indústria precisa expandir o foco econômico tradicional para incluir as dimensões ambientais, sociais e tecnológicas, a fim de criar um negócio mais sustentável (ELKINGTON, 1998). Com base em Elkington (1998), United Nations Environment Programme (2007), Bork (2015) e De Barba Jr. (2015), as dimensões ambiental, econômica e social são apresentadas a seguir.

A dimensão econômica considera a sustentabilidade financeira da empresa, incluindo seus custos de manutenção e seu lucro obtido com a venda de seus produtos e/ou serviços. Na dimensão ambiental, são considerados os impactos positivos e negativos sobre o meio ambiente como um todo (ar, água, solos etc.), provenientes dos processos de produção do produto ou da prestação de um serviço. Já na dimensão social, são considerados os impactos positivos e negativos causados à sociedade pela implantação e operação da empresa, como geração de emprego e renda, relação com as comunidades locais, valorização dos funcionários e preocupação com a segurança e satisfação de seus clientes, aumento da demanda por serviços básicos de saúde, educação e saneamento.

De acordo com estudo realizado por De Barba Jr. (2015), existem outras dimensões a serem levadas em conta na visão da sustentabilidade, sendo que a tecnológica é importante para o setor industrial. A dimensão tecnológica da sustentabilidade de um produto leva em consideração suas propriedades físicas (mecânica, térmica, elétrica etc.) e químicas (resistência à corrosão, oxidação etc.), além de sua durabilidade (por quanto tempo esse produto estará em condições de uso), facilidade de conserto, desmonte e reciclagem, entre outros.

O desenvolvimento de tecnologia sustentável é proposto pela análise da fonte causadora de impactos positivos e negativos sobre as dimensões ambiental, econômica e social sobre o desenvolvimento sustentável. O grau tecnológico influencia a demanda por matérias-primas, energia, transportes e infraestrutura, além dos fluxos de massa de materiais, emissões e outras formas de resíduos. Porém, a tecnologia não pode determinar os aspectos futuros da sustentabilidade, nem ser totalmente determinada pelos elementos do desenvolvimento sustentável. É um processo complexo, no qual existe uma influência mútua entre o desenvolvimento sustentável e a tecnologia (MUSANGO \& BRENT, 2011).

As empresas devem lidar ainda com um cenário cada vez mais competitivo em que a inovação em produtos busca a sustentabilidade como uma necessidade de sobrevivência em mercados consumidores (MEDEIROS et al., 2014).

Diante disso, deve-se considerar que produto sustentável é aquele que apresenta o melhor desempenho ambiental ao longo de seu ciclo de vida, com função, qualidade e nível de satisfação com igual grau de importância (GLSSALC, 2008).

Muitas vezes, o aspecto da sustentabilidade é negligenciado na fase de desenvolvimento de novos produtos, sendo que é nessa fase que as características iniciais da sustentabilidade do ciclo de vida do produto deveriam ser abordadas (GMELIN \& SEURING, 2014). 
De acordo com Ellram et al. (2008), é possível estabelecer e atingir metas de sustentabilidade no desenvolvimento de novos produtos sem deixar de lado as aspirações com a rentabilidade da organização e a qualidade de desempenho.

É importante considerar que a existência de objetivos estratégicos de negócio bem definidos para as três dimensões da sustentabilidade constitui-se como uma premissa para o desenvolvimento de um produto efetivamente sustentável. É difícil desenvolver um produto sustentável fora de um ambiente de negócio que não considere essa abordagem, que não contemple as dimensões ambiental, social e econômica (MARX \& PAULA, 2011).

\section{Compras públicas sustentáveis}

A compra pública sustentável é uma forma de integrar considerações e princípios de sustentabilidade em todos os estágios do processo da compra e contratação dos agentes públicos (de governo) com objetivo de reduzir impactos à saúde humana e ao meio ambiente. Ela permite $o$ atendimento das necessidades específicas dos consumidores finais por meio da compra do produto que oferece o maior número de benefícios para o ambiente e a sociedade (GLSSALC, 2008; EDLER \& GEORGHIOU, 2007; RAYMOND, 2008).

As compras públicas sustentáveis constituem relevante instrumento de contribuição para a reorganização da economia com novos paradigmas. No Brasil, inserem-se em um contexto de agendas nacionais que orientam as ações e políticas para o desenvolvimento sustentável (BRASIL, 2014; GELDERMAN et al., 2015; THAI, 2001).

Diante disso, as compras públicas sustentáveis representam a adequação da contratação ao que se chama consumo sustentável. Significa pensar a melhor proposta para a administração pública, levando-se em conta, além do menor preço, o custo como um todo, considerando a manutenção da vida no planeta e o
Desse modo, para se produzir um produto sustentável, é preciso que as empresas tenham a sustentabilidade, em suas três dimensões, bem sedimentada em seus planos estratégicos de negócios e que isso seja refletido no processo de desenvolvimento de produtos (AZEVEDO \& NOLASCO, 2009; MARX \& PAULA, 2011; DEMAJOROVIC \& MATURANA, 2009).

É importante conhecer os requisitos de sustentabilidade que devem ser incorporados no processo de desenvolvimento de produtos sustentáveis, pois eles serão utilizados para avaliar o desempenho ambiental desses novos produtos. Esses requisitos devem envolver a redução da poluição (resíduos, emissões atmosféricas e efluentes líquidos); a redução do consumo de água e energia; e a redução frequente dos acidentes ambientais (LAI \& WONG, 2012; ZHU et al., 2007).

bem-estar social. Ressalta-se que os recursos naturais do país e sua biodiversidade são públicos e devem ser preservados (BRASIL, 2014; FISHER, 2013; UTTAM; LE LANN ROOS, 2015).

O Decreto no 7.746 , de 5 de junho de 2012, que regulamentou o artigo 3ㅇ da Lei no 8.666 (Lei das Licitações), de 21 de junho de 1993, foi o qual estabeleceu critérios, práticas e diretrizes gerais para a promoção do desenvolvimento sustentável por meio das contratações efetuadas pelo governo no Brasil. O artigo 3ㅇdo decreto determinou a forma de instituir os critérios e as práticas de sustentabilidade para o governo (CARDOSO, 2016).

Segundo Cardoso (2016), os gestores ainda possuem dúvidas de como especificar os critérios e requisitos sustentáveis no processo de compras por meio das modalidades de licitações existentes. Ainda segundo o autor, o Ministério do Planejamento tentou demonstrar a aplicação dessas especificações e disponibilizou alguns casos frequentes das compras sustentáveis comuns que apresentam os critérios de sustentabilidade comumente utilizados nas compras governamentais.

\section{MATERIAIS E MÉTODOS}

Optou-se por utilizar a técnica de mapa cognitivo por elicitar o conhecimento existente de es- pecialistas sobre um determinado contexto, além de proporcionar um processo de aprendizagem e 
construção de estratégias para tomada de decisão. O mapa cognitivo foi usado como ferramenta para a definição dos requisitos de sustentabilidade a partir de entrevistas com especialistas da área de sustentabilidade vinculados a empresas do setor industrial escolhido.
$\mathrm{Na}$ pesquisa, utilizou-se a entrevista semiestruturada, que permitiu explorar várias visões para o mesmo tema. Com isso, foi possível construir um modelo que estimulou os sentimentos e valores dos especialistas envolvidos a respeito do problema em que estão inseridos, mas sem a necessidade de ditar normas.

\section{Construção do mapa cognitivo}

Na construção do mapa cognitivo, obedeceram-se a cinco etapas.

\section{Etapa 1: Definição do problema e seu contexto}

Considerando o contexto estabelecido, foi definido o problema pelo facilitador. No momento da entrevista com cada especialista, por meio de uma abordagem

\section{Passo 1: Definição dos atores envolvidos}

Buscou-se selecionar especialistas da área de sustentabilidade com atuação no setor industrial. Esses atores empática e não impositiva, o facilitador apresentou a proposta de rótulo do problema, que foi validada por cada ator envolvido.

foram escolhidos com base em sua experiência profissional e área de atuação.

\section{Passo 2: Elaboração do questionário para ambientação do tema}

Tendo em vista facilitar a exploração dos elementos importantes, elaborou-se um questionário de ambientação que foi encaminhado por e-mail antes da entrevista com cada especialista. Esse questionário foi elaborado com perguntas sobre o tema contextualizado nessa pesquisa e continha quatro perguntas. Seu objetivo foi levantar questões sobre o tema, proporcionando a reflexão sobre as possibilidades atuais e futuras dos valores, das importâncias, a fim de criar ideias e soluções para o problema.
Posteriormente, nas entrevistas com os especialistas e o facilitador, desenvolveu-se a metodologia para geração do mapa cognitivo. Esse tipo de estratégia possibilitou absorver várias questões que envolviam o problema, de maneira que se expandisse e explorasse a criatividade de cada entrevistado. A quantidade de elementos primários de avaliação (EPA) foi fundamental para qualificar o mapa cognitivo individual e o congregado.

\section{Etapa 2: Definição dos elementos primários de avaliação e construção dos conceitos a partir desses elementos}

Os EPA constituem objetivos, valores e metas referentes ao problema considerando a visão dos especialistas. Aproveitando o objeto definido na Etapa 1 como fonte de elaboração do raciocínio sobre o tema, foram levantados tópicos que influenciaram nessa temática. O primeiro momento foi um brainstorming, permitindo que a conversa sobre o tema fosse naturalmente sendo desenvolvida.

Durante o diálogo, foram feitas perguntas específicas (Quadro 1). O objetivo dessas perguntas foi possibilitar a definição dos EPA. No final desse primeiro momento, foram apresentados e validados, por cada especialista, os elementos identificados.
Essa etapa teve a finalidade de visualizar a problemática na qual se encontra inserido e descrevê-la, alcançando seu entendimento para, assim, ter a capacidade de proferir suas decisões estratégicas fundamentadas no estudo realizado, identificando critérios de maior relevância a serem considerados na decisão dos requisitos de sustentabilidade para produtos do setor industrial selecionado.

Os conceitos foram elaborados a partir da utilização de um verbo no infinitivo em cada um dos EPA para que destacassem uma orientação à ação. 


\section{Etapa 3: Hierarquização dos conceitos}

Aqui o facilitador fez questionamentos a cada especialista para obtenção de conceitos meio e fim. Fundamentado em um conceito, o facilitador direcionou os especialistas a pensar "por que o conceito é importante" e "como realizar tal conceito".

Após essa etapa, foi possível gerar os mapas individuais que expressam, por meio de mapas cognitivos, os requi-

\section{Etapa 4: Construção do mapa cognitivo congregado}

A construção do mapa ocorreu após o estabelecimento dos conceitos meio e fim, identificados na Etapa 3. Foi realizada apenas pelo facilitador, sem a participação dos especialistas. Os conceitos que eram comuns a mais

\section{Etapa 5: Análise do mapa cognitivo congregado}

Para esta pesquisa, os mapas foram analisados de acordo com as recomendações de Cruz (2011), que estabelece três passos para analisar um mapa cognitivo congregado: identificações dos clusters, das linhas de argumentação e dos ramos.

\section{Passo 1: Identificação dos clusters}

Os agrupamentos, denominados de clusters, são identificados visualmente ou por análise do conteúdo dos mapas. A separação dos conceitos em clusters tem o objetivo de diminuir a complexidade que existe ao se tratar do mapa como um todo.

Para Gomes et al. (2009), um mapa cognitivo pode ser visto como um conjunto de clusters. Os clusters podem sitos e outros pontos relevantes na visão dos especialistas sobre o problema abordado. Cada mapa, após sua finalização, foi validado pelo especialista que o gerou. Os mapas cognitivos individuais e o congregado, feito por meio da união dos mapas individuais, foram construídos por meio do software CmapTools ${ }^{\circledR}$, versão 5.05.01.

de um especialista foram colocados uma única vez, com o melhoramento da redação do conceito no mapa congregado. Após a finalização do mapa cognitivo congregado, ele foi validado por todos os especialistas.

Esse processo de análise serviu para identificar os requisitos de sustentabilidade para as dimensões ambiental, econômica, social e tecnológica. E ainda as percepções do setor industrial sobre compras públicas sustentáveis.

ser identificados em função de uma grande densidade de ligações entre conceitos. Outro modo de identificá-los é com base em conceitos com sentidos semelhantes para obtenção dos objetivos finais. Com isso, foi possível a identificação de nichos de conceitos, determinando o cluster e facilitando a identificação visual das estratégias para cada um deles, como observado na Figura 1.

\section{Passo 2: Identificação das linhas de argumentação e dos ramos}

Quadro 1 - Estratégias para identificar elementos primários de avaliação (19).

Aspectos desejáveis

Ações

Dificuldades

Consequências

Meta/restrições/linhas gerais

Objetivos estratégicos

Perspectivas diferentes
Quais são os aspectos que os senhores

gostariam de levar em consideração em seu problema?

Quais características distinguem uma ação (potencial ou fictícia) boa de uma ruim?

Quais são as maiores dificuldades com relação ao estado atual?

Quais consequências das ações são boas/ruins/inaceitáveis?

Quais são as metas/restrições/e linhas gerais adotadas pelos entrevistados?

Quais são os objetivos estratégicos neste contexto?

Quais são os aspectos desejáveis/ações/dificuldades/etc., segundo a perspectiva de outro ator, para o entrevistado? 
A análise avançada dos mapas cognitivos teve como característica a identificação dos eixos de avaliação do problema e o conteúdo do mapa. Nesta análise, buscou-se a identificação das linhas de argumentação.

Segundo Lima (2008), essas linhas compreendem a sequência de conceitos que se conectam entre si por uma relação de influência e que formam uma linha de raciocínio de meios e fins com início em um conceito-cauda e término em um conceito-cabeça. Tomando como exemplo a Figura 1, é possível verificar seis linhas de argumentação (C9-C7-C5-C1-C4), (C9-C10-C8-C5-C1-C4), (C6-C1-C4), (C13-C11-C2-C4), (C12-C2-C4), (C17-C16-C15-C14-C3-C4).

Já a identificação dos ramos em um mapa cognitivo ocorre com base nas similaridades dos interesses retratados nas linhas de argumentação. Pode, dessa maneira, coincidir com uma dessas linhas ou englobar mais de uma delas, dada a proximidade conceitual existente em um conjunto de linhas. Assim, essa identificação ocorre basicamente da análise de conteúdo do mapa (ENSSLIN et al., 2001). A Figura 2 aborda um exemplo de identificação de ramos em um mapa cognitivo. No exemplo, para simplificação, exploram-se apenas os polos positivos dos conceitos referentes a uma decisão de aquisição de um computador portátil (LIMA, 2008).

Com isso, após a finalização da análise do mapa cognitivo congregado, foi possível levantar os requisitos de sustentabilidade para cada dimensão mencionada pelos especialistas, por meio da avaliação do conteúdo das linhas de argumentação. Além disso, utilizando os clusters e as linhas de argumentação, foi possível levantar as percepções do setor industrial, selecionado para esta pesquisa, com relação às compras públicas sustentáveis.

Identificação das tendências de priorização dos requisitos de sustentabilidade

Utilizaram-se os mapas cognitivos individuais e, de acordo com Bork (2015), em trabalho similar realizado, considerando-se o que o mapa cognitivo representa os conceitos e as proposições de

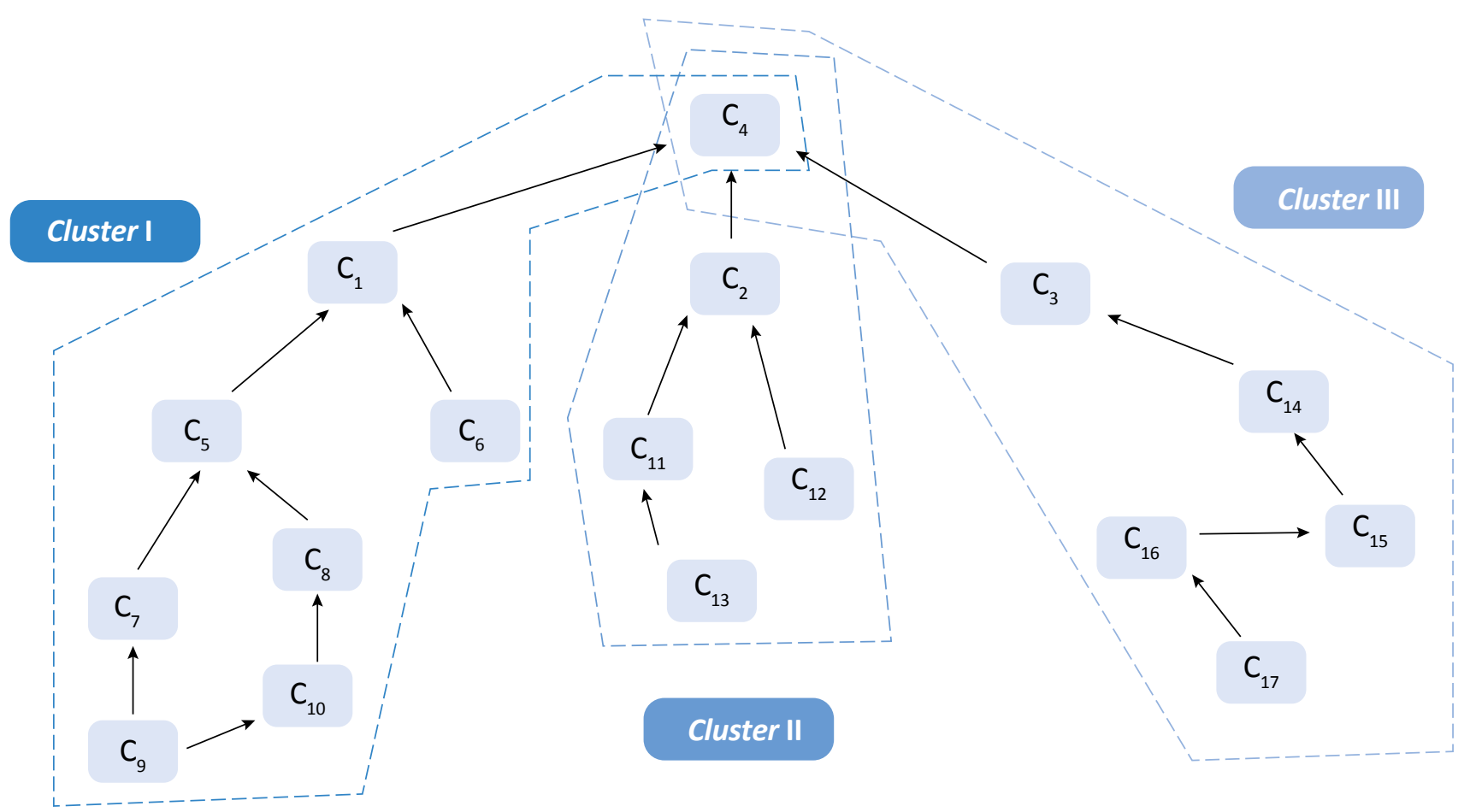

Fonte: LIMA (2008)

Figura 1 - Definição de clusters do mapa cognitivo 
cada entrevistado a respeito do tema em discussão. Podem-se realizar a contagem de conceitos, a contagem dos conceitos mais repetidos nas entrevistas, a contagem dos conceitos repetidos em cada aspecto analisado, entre outros (BORK, 2015).
A identificação das tendências de priorização dos requisitos de sustentabilidade ocorreu por meio da contagem dos conceitos que se repetiram nas dimensões ambiental, econômica, social e tecnológica.

\section{RESULTADOS E DISCUSSÃO}

A seguir, serão apresentados e discutidos os resultados obtidos.

\section{Definição dos requisitos de sustentabilidade para o setor têxtil e de confecção}

Essa fase teve o objetivo de identificar os requisitos de sustentabilidade para servir de subsídio nas discussões governamentais sobre compras públicas sustentáveis e de referência para o setor. O mapa cognitivo foi a ferramenta para essa identificação, com base em entrevistas com especialistas do setor selecionado.
Para estabelecer requisitos de sustentabilidade para produtos sustentáveis em um ambiente técnico, construiu-se o mapa cognitivo congregado a partir do cognitivo individual de especialistas qualificados com interesses distintos.

Esta análise teve como foco um problema complexo, pois envolve especialistas da área de sustentabilidade de dife-

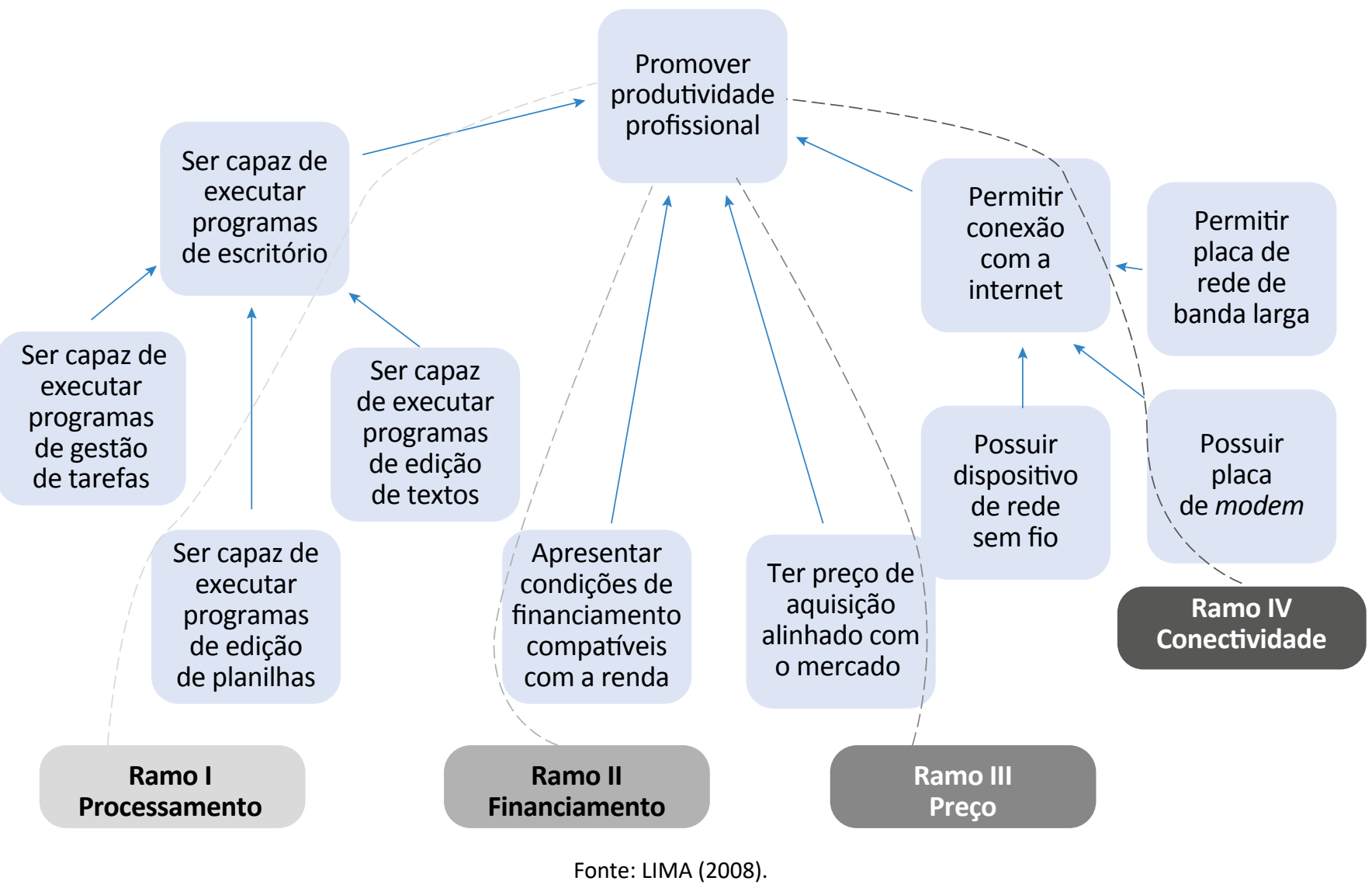

Figura 2 - Exemplo de identificação de ramos. 
rentes empresas, de um mesmo setor industrial da economia brasileira, com percepções e interesses distintos sobre o assunto, tanto no campo técnico quanto político, de compras públicas sustentáveis. Utilizou-se como direcionador o rótulo do problema: Definição de requisitos de sustentabilidade nas compras governamentais de produtos do setor têxtil e de confecção da indústria brasileira.
O trabalho buscou desenvolver a complexidade conjunta aos diversos interesses de um problema dentro de várias visões dos atores no contexto. Contemplou-se a subjetividade dos especialistas, levando-se em consideração seus objetivos, seus preconceitos, suas crenças, seus valores, sua cultura e sua intuição.

\section{Construção do mapa cognitivo}

Na construção do mapa cognitivo, obedeceram-se às etapas descritas na sequência.

\section{Etapa 1: Definição do problema e seu contexto}

É importante que a CNI esteja munida de informações, práticas e realidades de cada setor nos diversos fóruns governamentais em que participa defendendo o interesse do setor industrial para garantir que as particularidades sejam levadas em consideração na formulação de políticas públicas.

Nesse contexto, está em atividade o Grupo de Trabalho de Produção e Consumo Sustentável, do qual a CNI faz parte, que está definindo regras para as compras públicas sustentáveis. De forma particular, o setor têxtil e de confecção foi escolhido para ser um dos primeiros a ser objeto de norma específica, devido ao volume de compras de produtos desse segmento que o governo

\section{Passo 1: Definição dos atores envolvidos}

Selecionou-se a ABIT, que participa do Grupo de TrabaIho de Produção e Consumo Sustentável, para auxiliar na escolha dos especialistas. Alguns especialistas que atuam na ABIT com o objetivo de estudar e propor, tecnicamente, posicionamentos e caminhos a serem considerados nas discussões foram indicados para a pesquisa.

Com isso, foram selecionados, pela ABIT e pelo autor, seis especialistas de empresas diferentes desse setor para serem os atores a gerarem o mapa cognitivo individual para o problema apontado. Esse número foi definido em virtude da disponibilidade de tempo dos especialistas e de seu relacionamento com a associação. A seguir, é apresentado o perfil dos selecionados.

- Especialista 1: Profissional com nível superior na área de engenharia e experiência de mais de 20 anos na área de sustentabilidade do setor têxtil e de confecção; realiza. Parte dessas regras envolvem requisitos de sustentabilidade de produtos que serão exigidos dos fornecedores. Construir uma política de compras públicas sustentáveis realista corrobora o pensamento de Fischer (2013), pois as compras públicas têm de deixar de ser apenas políticas para serem efetivas.

Com isso, é importante que a CNI juntamente com o setor determinem os requisitos mais relevantes e aplicáveis na indústria têxtil e de confecção. Diante desse contexto, o problema proposto e validado com cada especialista foi: "Definir requisitos de sustentabilidade para serem considerados nas compras governamentais de produtos do setor têxtil e de confecção da indústria brasileira".

- Especialista 2: Profissional com nível de pós-graduação na área de engenharia e meio ambiente e experiência superior a dez anos na área de pesquisa e ensino no setor têxtil e de confecção;

- Especialista 3: Profissional com nível superior na área de economia e meio ambiente e experiência superior a dez anos na área de sustentabilidade do setor têxtil e de confecção;

- Especialista 4: Proprietário de empresa do setor têxtil e de confecção há mais de 30 anos; sua companhia obteve diversos prêmios de sustentabilidade nos últimos dez anos;

- Especialista 5: Profissional com pós-graduação na área de inovação e tecnologia e experiência superior a 15 anos na área de pesquisa e ensino no setor têxtil e de confecção; 
- Especialista 6: Profissional com nível superior na área de sustentabilidade e experiência superior a cinco anos na área de sustentabilidade do setor têxtil e de confecção.

\section{Passo 2: Elaboração do questionário para ambientação do tema}

Seguindo a metodologia, o questionário foi elaborado pelo facilitador com as seguintes perguntas:

1. Em sua opinião, o que deve ser levado em consideração quando falamos de requisitos de sustentabilidade para produtos do setor?;
2. Quais seriam os requisitos de sustentabilidade que devem ser atendidos por um produto para ser considerado sustentável?;

3. Quais seriam os problemas enfrentados para definir requisitos de sustentabilidade?;

4. Quais os problemas, as dificuldades ou as restrições relacionadas ao estado atual?

\section{Etapa 2: Definição dos elementos primários de avaliação e construção dos conceitos}

Nessa etapa, abordou-se a temática de "Definir requisitos de sustentabilidade para serem considerados nas compras governamentais de produtos do setor têxtil e de confeç̧ão da indústria brasileira" como fonte de elaboração do raciocínio sobre o

\section{Etapa 3: Hierarquização dos conceitos}

Seguindo a metodologia para essa etapa, foi possível construir o mapa cognitivo individual fundamentado

\section{Etapa 4: Construção do mapa cognitivo congregado}

A construção do mapa, conforme a metodologia proposta, ocorreu sem a participação dos especialistas. tema e posterior levantamento dos EPA e construção dos conceitos.

Os conceitos construídos a partir dos EPA definidos pelo grupo são apresentados no Quadro 2.

nos EPA listados por cada especialista, conforme pode ser observado nas Figuras de 3 a 8.

O mapa cognitivo congregado foi validado por todos os especialistas e pode ser analisado na Figura 9.

\section{Etapa 5: Análise do mapa cognitivo congregado}

Em acordo com a metodologia proposta foi realizada a análise do mapa.

\section{Passo 1: Identificação dos clusters}

Com a finalização do mapa cognitivo congregado, obteve-se a visualização dos conceitos. Com isso, foi possível a identificação de nichos de conceitos, os clusters, como pode ser visto na Figura 10.

Os clusters ficaram divididos em quatro grupos, que correspondem às ideias consolidadas e validadas pelos especialistas com o facilitador. Os clusters identificados foram:

- Competitividade: apresenta a preocupação com a concorrência nos processos licitatórios;
- Requisitos de sustentabilidade: aborda a visão do grupo com a definição de critérios a serem considerados no processo de compras governamentais;

- Revisão de normas: apresenta uma reivindicação do grupo e alguns caminhos a seguir;

- Definição do conceito de produto sustentável: ressalta a importância de definição do conceito de produto sustentável para o setor têxtil e de confecção. 


\section{Passo 2: Identificação das linhas de argumentação e dos ramos}

O Quadro 3 apresenta as linhas de argumentação do mapa cognitivo congregado para o setor têxtil e de confecção. No caso estudado, as linhas de argumentação são iguais aos ramos. Dessa forma, considerou-se a análise do mapa cognitivo congregado encerrada.
De posse das linhas de argumentação, verificaram-se as percepções do setor têxtil e de confecção sobre compras públicas sustentáveis. Para isso, analisou-se o conteúdo de todas as linhas de argumentação, separando-as em blocos. Os resultados dessa análise podem ser vistos no Quadro 4.

Quadro 2 - Lista de elementos primários de avaliação definidos por cada especialista.

\begin{tabular}{|c|c|c|}
\hline Identificação & $\begin{array}{l}\text { Número do conceito } \\
\text { no mapa cognitivo } \\
\text { individual }\end{array}$ & Elementos primários de avaliação transformados em conceitos \\
\hline Esp. 01 & 2 & ter regras claras no processo de compra / ... não ter regra \\
\hline Esp. 01 & 3 & ter incentivos fiscais para empresas mais sustentáveis / ... não ter incentivos \\
\hline Esp. 01 & 4 & considerar autodeclaração para empresas / ... não considerar \\
\hline Esp. 01 & 13 & ter padronização dos moldes / ... não ter padronização \\
\hline Esp. 02 & 2 & garantir a competitividade da indústria nacional / ... não garantir \\
\hline Esp. 02 & 3 & ter incentivos fiscais para empresas sustentáveis / ... não ter \\
\hline Esp. 02 & 4 & considerar a ecoeficiência /... não considerar \\
\hline Esp. 02 & 6 & definir regras claras e objetivas / ... não definir \\
\hline Esp. 02 & 8 & considerar processo de fabricação de cada material / ... não considerar \\
\hline Esp. 02 & 9 & definir métricas dos requisitos (indicadores) / ... não definir \\
\hline Esp. 03 & 2 & definir regras claras / ... não definir \\
\hline Esp. 03 & 4 & considerar normas internacionais / ... não considerar \\
\hline Esp. 03 & 7 & definir o que é sustentabilidade para o setor / ... não definir \\
\hline Esp. 04 & 2 & internalizar sustentabilidade nas empresas / ... não considerar \\
\hline Esp. 04 & 5 & considerar o produto sustentável / ... não considerar \\
\hline Esp. 04 & 13 & diversificação de produtos / ... não ter \\
\hline Esp. 04 & 14 & ter planejamento estratégico e financeiro do produto / ... não ter \\
\hline Esp. 04 & 16 & ter situação financeira saudável / ... não ter \\
\hline Esp. 05 & 3 & definir conceito de sustentabilidade para o setor / ... não definir \\
\hline Esp. 05 & 8 & definir incentivos para empresas mais sustentáveis / ... não definir \\
\hline Esp. 05 & 11 & definir métrica para os requisitos / ... não definir \\
\hline Esp. 06 & 2 & ter sustentabilidade como diferencial competitivo / ... não ter \\
\hline Esp. 06 & 3 & ter incentivos para empresas mais sustentáveis / ... não ter \\
\hline Esp. 06 & 4 & revisar as normas existentes / ... não revisar \\
\hline Esp. 06 & 6 & definir conceito de sustentabilidade para o setor / ... não definir \\
\hline Esp. 06 & 7 & definir regras claras / ... não definir \\
\hline
\end{tabular}

Esp.: especialista. 


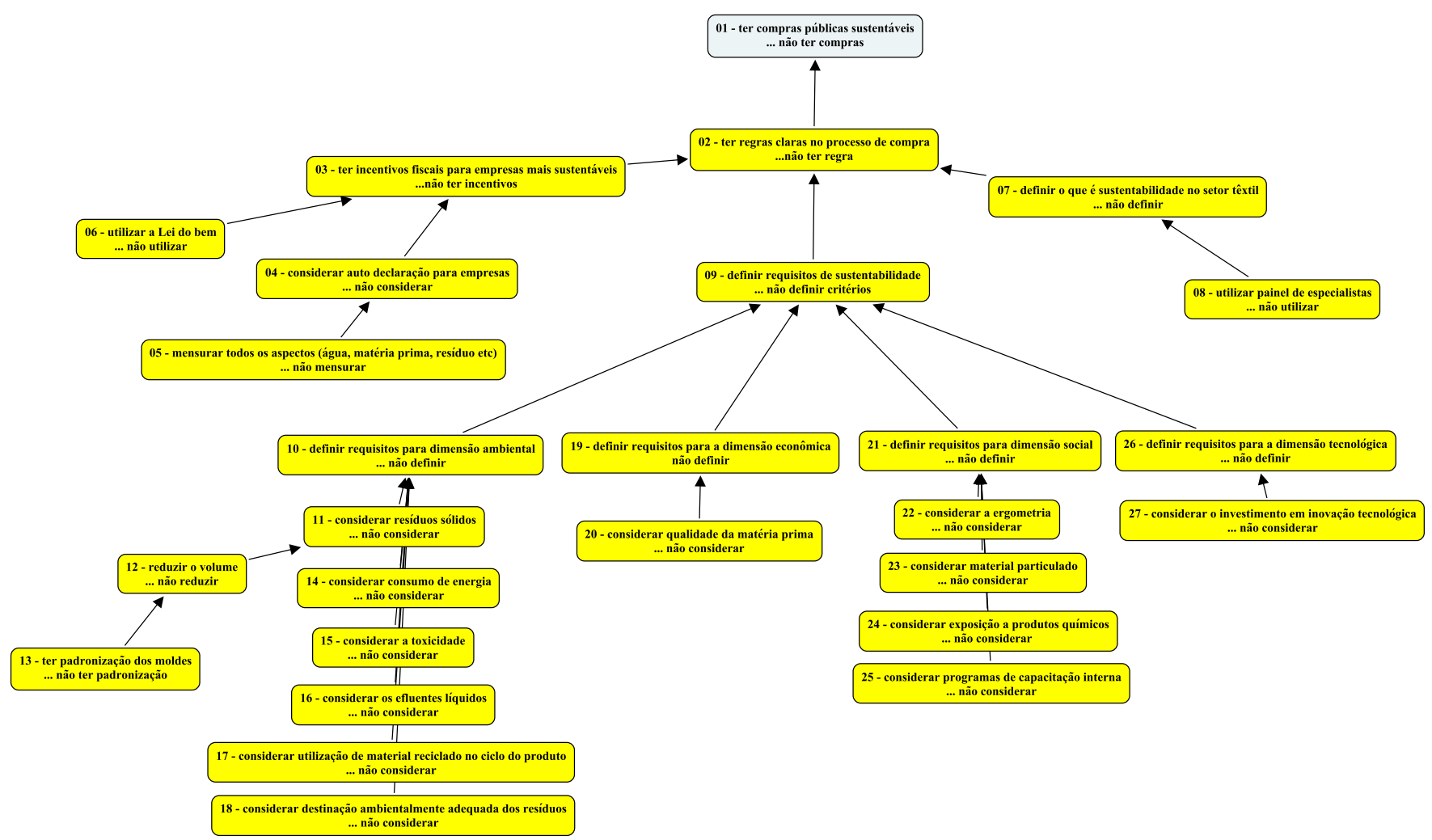

Figura 3 - Mapa cognitivo individual do especialista 1.

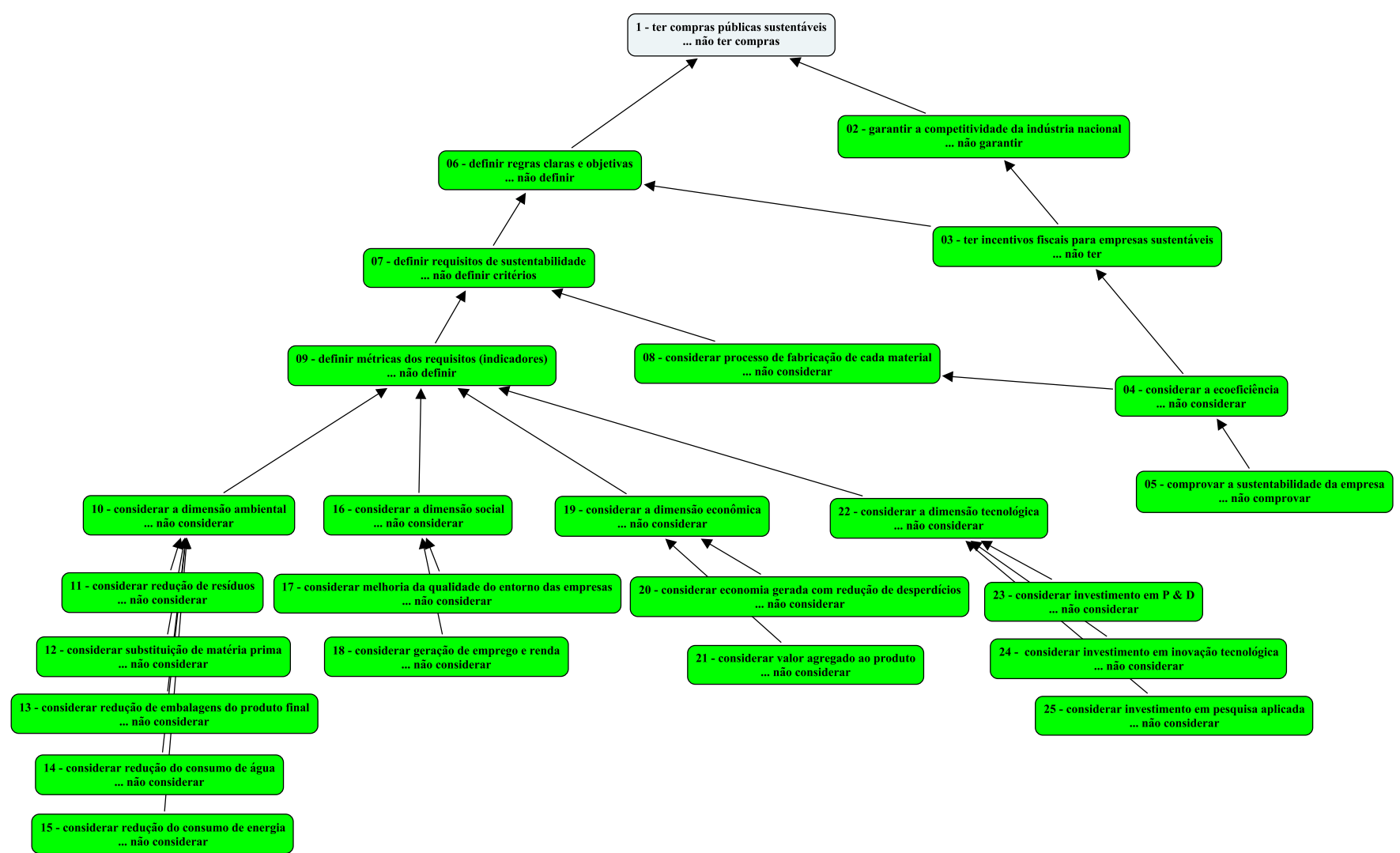

Figura 4 - Mapa cognitivo individual do especialista 2. 


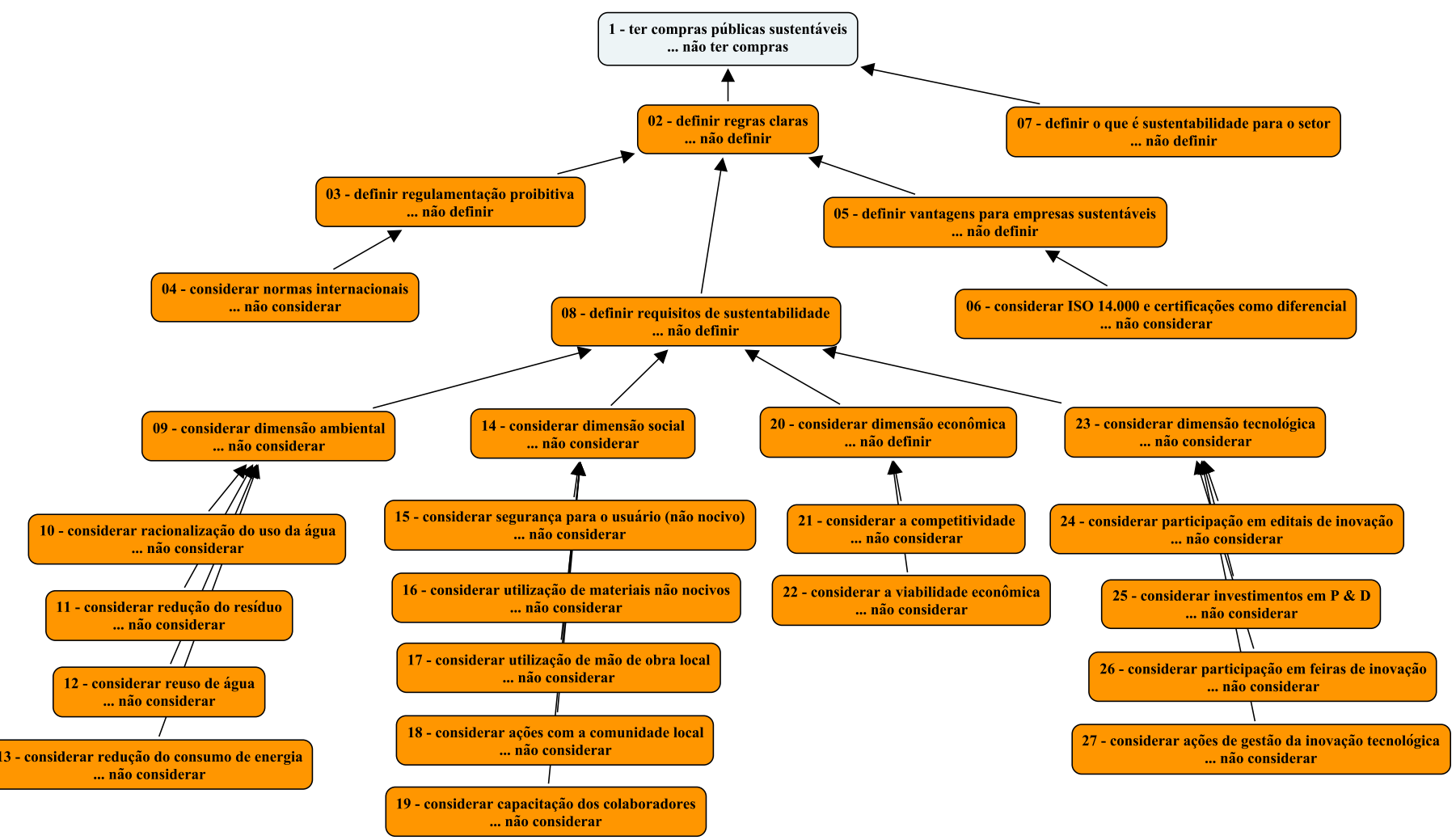

Figura 5 - Mapa cognitivo individual do especialista 3.

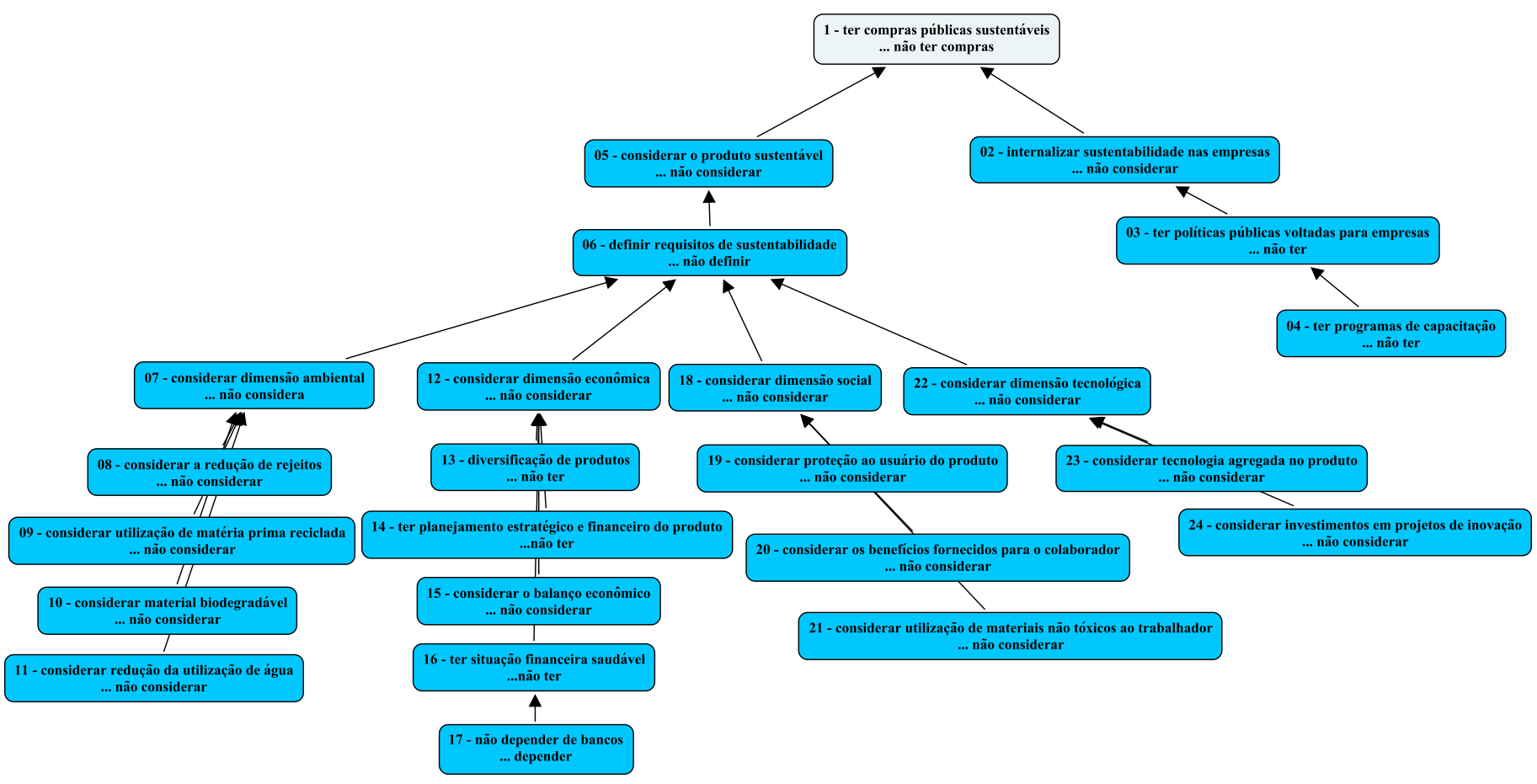

Figura 6-Mapa cognitivo individual do especialista 4. 
Ainda utilizando as linhas de argumentação do mapa congregado, foi possível gerar a lista dos requisitos de sustentabilidade. Para isso, utilizaram-se as linhas 7, 8 , 9 e 10, pertencentes a esse cluster. Os requisitos de sustentabilidade estão listados nos conceitos cujas numerações estão entre parênteses, nas respectivas linhas de argumentação, que são o 35 e do 38 ao 52 na dimensão ambiental; do 54 ao 66 na econômica; do 68 ao 86 na social; e do 88 ao 95 na tecnológica. Com isso, obtiveram-se, para as dimensões ambiental, social, econômica e tecnológica, respectivamente, 16, 19, 11 e 8 requisitos.

Por fim, utilizando-se os mapas cognitivos individuais, realizou-se a contagem dos conceitos que se repetiram na entrevista com os especialistas. Dessa maneira, identificou-se a tendência de priorização dos requisitos de sustentabilidade.

O Quadro 5 apresenta a lista dos requisitos identificados, bem como a tendência de priorização deles.

Analisando a densidade dos conceitos, no mapa cognitivo congregado, para cada cluster, identificaram-se tendências que foram: requisitos de sustentabilidade com $73 \%$, competitividade com $12 \%$, definição do conceito de produto sustentável com $10 \%$ e revisão de normas com $5 \%$. Elas retratam as ideias e percepções do grupo, de forma consensual, sobre o problema.

O valor para o cluster de requisitos em sustentabilidade foi alto por conta do elevado número de conceitos para cada dimensão, listados pelos especialistas.

O enfoque de cada especialista na construção de cada mapa, e assim na construção do mapa congregado, identificou que o cluster de requisitos de sustentabilidade é o que apresenta o maior número de conceitos, destacando-se que a visão de sustentabilidade do grupo aborda a dimensão tecnológica, além das tradicionalmente conhecidas. O trabalho de De Barba Jr. (2015) colabora com esse resultado, pois nele se identificou, na literatura, outras dimensões que devem ser consideradas na busca pela sustentabilidade de produtos no setor industrial, de forma particular a dimensão tecnológica que influencia diretamente a indústria.

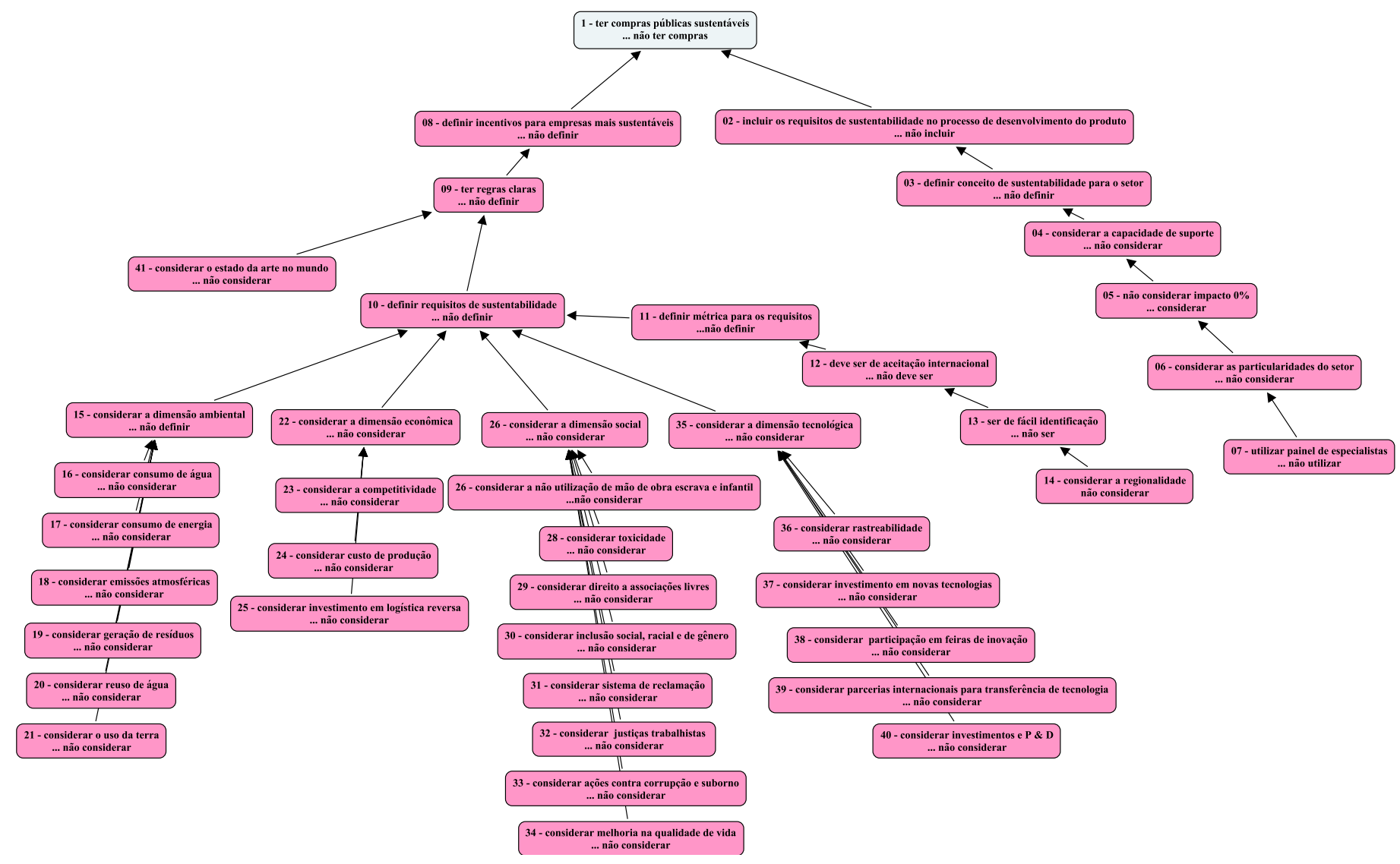

Figura 7 - Mapa cognitivo individual do especialista 5. 
Também vai ao encontro com o que diz o trabalho do Governos Locais pela Sustentabilidade Secretariado para América Latina e Caribe (2008), que coloca que um produto pode ser considerado como sustentável mesmo que não aborde os três pilares da sustentabilidade. Isso demonstra que o setor têxtil e de confecção está englobando não somente os três pilares, mas está indo além e considerando a dimensão tecnológica como parte essencial para a sustentabilidade.

Analisando as linhas de argumentação que compõem esse cluster, percebeu-se que é preciso estabelecer uma métrica para os requisitos e também fazer com que sejam de aceitação internacional e de fácil identi- ficação e que considerem as particularidades de cada região, o que vai ao encontro das considerações de Van Weenen (1995) de que é preciso que se incorporem ao processo de desenvolvimento de produtos sustentáveis, logo no início, todos os fatores importantes para que se possa otimizar a sustentabilidade do produto.

Isso reflete a preocupação do setor com a definição de critérios a serem considerados no processo de compras governamentais; conforme destacam Uttam e Le Lann Roos (2015), é importante que se tenha um diálogo entre o fornecedor e o comprador para a definição dos principais requisitos. A análise da repetição dos requisitos, considerando o mapa de cada especialista, revela

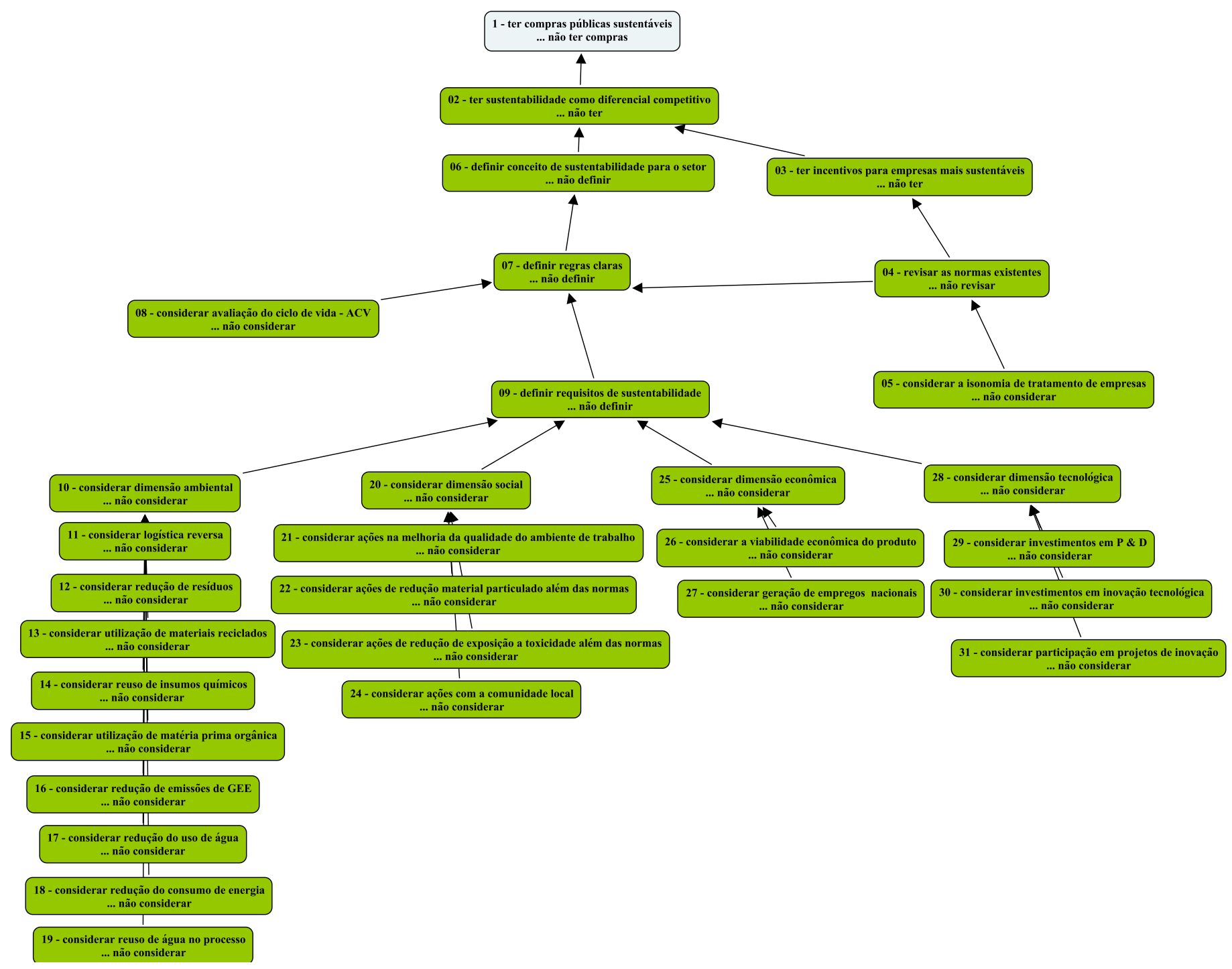

Figura 8 - Mapa cognitivo individual do especialista 5. 
que existe uma tendência de priorização, que precisa ser confirmada, a saber:

- Na dimensão ambiental, foram os requisitos redução de resíduos, consumo de energia elétrica e redução do uso de água os mais citados;

- Na dimensão econômica, foram os requisitos viabilidade econômica do produto e produtos e processos competitivos os mais mencionados;

- Na dimensão social, foram os requisitos utilização de materiais não nocivos à saúde humana, redução do material particulado, realização de programas de capacitação interna, segurança para o usuário (não nocivo) e realização de ações com a comunidade local os mais citados;
- Na dimensão tecnológica, foram os requisitos investimento em inovação tecnológica, investimento em $P \& D$ e participação em editais de inovação os mais repetidos.

Esse levantamento é um indicativo de quais seriam os requisitos que devem ser abordados pelo governo, porém é necessária uma discussão muito mais ampla e que envolva maior participação do setor para definir aqueles que são prioritários e aplicáveis atualmente.

O cluster de competitividade retratou como essa área é relevante para o setor, pois, nas compras governamentais, os importadores não são tratados de forma diferenciada dos produtores nacionais. Esse fato colabora para a perda de competitividade da indústria nacional, que é afetada por todas as normas e impostos inerentes a um produtor nacional, fato que não incorre so-

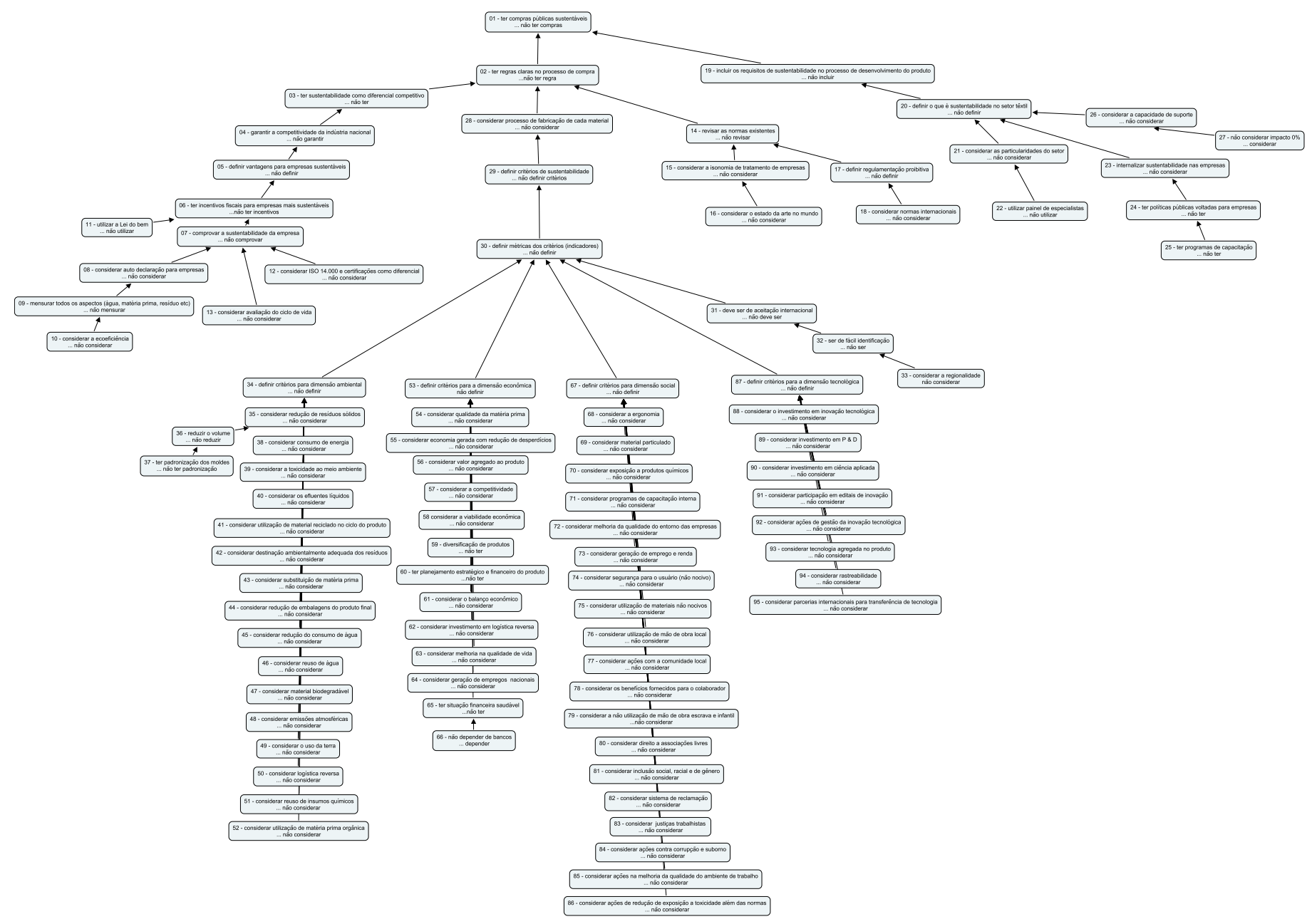

Figura 9- Mapa cognitivo congregado. 
bre os importadores e, com isso, conseguem um preço mais competitivo.

A análise das linhas de argumentação desse cluster revelou ainda que é importante o estabelecimento de incentivos fiscais para empresas que comprovem a sustentabilidade de seus produtos e processos, seja por meio de certificações como as da série International Organization for Standardization (ISO), seja por um

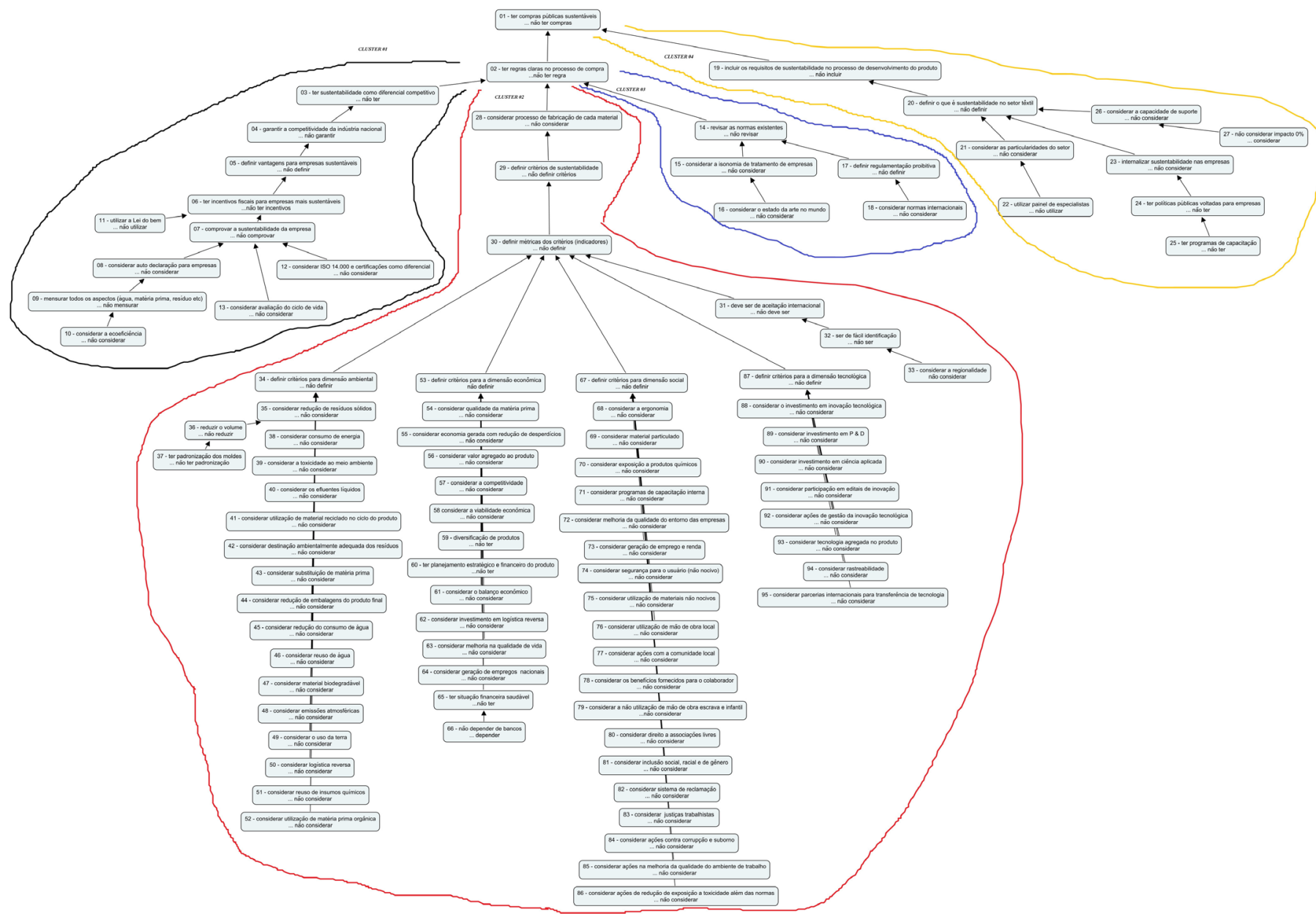

Figura 10 - Mapa cognitivo com cluster.

Quadro 3 - Linhas de argumentação.

\begin{tabular}{|l|c|c|c|}
\hline Numeração & Linha de argumentação & Numeração & Linha de argumentação \\
\hline 1 & $1-2-3-4-5-6-7-8-9-10$ & 9 & $1-2-28-29-30-68-(67$ ao 86) \\
\hline 2 & $1-2-3-4-5-6-11$ & 10 & $1-2-28-29-30-89-(90$ ao 95) \\
\hline 3 & $1-2-3-4-5-6-7-12$ & 11 & $1-2-14-15-16$ \\
\hline 5 & $1-2-3-4-5-6-7-13$ & 12 & $1-2-14-17-18$ \\
\hline 6 & $1-2-28-29-30-31-32-33$ & 13 & $1-19-20-21-22$ \\
\hline 8 & $1-2-28-29-30-34-35-36-37$ & 14 & $1-19-20-23-24-25$ \\
\hline
\end{tabular}


processo de autodeclaração, por intermédio da utilização de ferramentas de sustentabilidade, como a avaliação do ciclo de vida (ACV).

Outro ponto levantado pela análise do mapa congregado foi o cluster de definição do conceito de produto sustentável. Esse ponto é relevante para o setor, pois apresenta a necessidade imperiosa do governo de definir exatamente o que ele considera como produto sustentável na área têxtil e de confecção, uma vez que quem estabelece as regras do processo licitatório é o governo. Porém, essa definição deve acontecer levando em consideração as particularidades do segmento, incorporando ao processo de discussão os especialistas desse setor para auxiliar na definição.

Verificou-se ainda a necessidade de internalização da sustentabilidade pelas empresas do setor, necessitando, para isso, do apoio do governo com o estabeleci- mento de políticas públicas voltadas a essa demanda e a disponibilização de cursos de capacitação nessa temática para a cadeia produtiva.

Por fim, o cluster de revisão de normas, que, apesar de possuir a menor quantidade de conceitos, apresenta informações importantes para uma boa estratégia de representação da CNI e da ABIT. Já existem vários estados da federação brasileira com legislações específicas para compras governamentais e que exigem requisitos que foram estabelecidos sem levar em consideração as particularidades do setor. As linhas de argumentação desse cluster revelaram a necessidade de revisão dessas normas com base na realidade da indústria e de experiências internacionais, além de reforçar a necessidade de tratamento diferenciado para empresas nacionais frente às internacionais, incluindo o estabelecimento de normas proibitivas.

\section{CONCLUSÃO}

Este trabalho evidenciou os requisitos de sustentabilidade e suas tendências de priorização, na visão do setor industrial têxtil e de confecção, que servirá de subsídio nas discussões e negociações governamentais sobre compras públicas sustentáveis e que poderão ser utilizados como referência para esse setor. Cabe ressal-

Quadro 4 - Mapeamento das percepções do setor têxtil e de confecção.

\begin{tabular}{|l|c|c|}
\hline Numeração & Linha de argumentação & Percepção \\
\hline 1 & $1-2-3-4-5-6-7-8-9-10$ & \\
\hline 2 & $1-2-3-4-5-6-11$ & Relacionado a competitividade e meios de incentivar a \\
sustentabilidade no setor.
\end{tabular}


Quadro 5 - Lista de requisitos de sustentabilidade e sua tendência de priorização para o setor têxtil e de confecção.

\begin{tabular}{|c|c|c|c|c|}
\hline Repetições & Ambiental & Econômica & Social & Tecnológica \\
\hline 6 & $\begin{array}{l}\text { Redução de resíduos } \\
\text { sólidos }\end{array}$ & - & - & - \\
\hline 5 & $\begin{array}{l}\text { Redução do consumo } \\
\text { de energia elétrica e do } \\
\text { consumo de água }\end{array}$ & - & - & $\begin{array}{l}\text { Investimento em } \\
\text { inovação tecnológica }\end{array}$ \\
\hline 4 & - & - & - & Investimento em P\&D \\
\hline 3 & $\begin{array}{l}\text { Utilização de material } \\
\text { reciclado no ciclo do } \\
\text { produto; reúso } \\
\text { de água }\end{array}$ & $\begin{array}{l}\text { Viabilidade econômica } \\
\text { do produto }\end{array}$ & $\begin{array}{c}\text { Utilização de materiais } \\
\text { não nocivos à saúde } \\
\text { humana }\end{array}$ & - \\
\hline 2 & $\begin{array}{l}\text { Redução de emissões } \\
\text { atmosféricas }\end{array}$ & $\begin{array}{l}\text { Produtos e processos } \\
\text { competitivos }\end{array}$ & $\begin{array}{l}\text { Redução do material } \\
\text { particulado; } \\
\text { capacitação interna; } \\
\text { segurança para } \\
\text { o usuário (não } \\
\text { nocivo); ações com a } \\
\text { comunidade local }\end{array}$ & $\begin{array}{c}\text { Participação em editais } \\
\text { de inovação }\end{array}$ \\
\hline 1 & $\begin{array}{l}\text { Utilização de matérias- } \\
\text { primas e insumos } \\
\text { não tóxico ao meio } \\
\text { ambiente; tratamento } \\
\text { dos efluentes } \\
\text { líquidos; destinação } \\
\text { ambientalmente } \\
\text { adequada dos resíduos; } \\
\text { substituição de } \\
\text { matérias-primas no } \\
\text { processo produtivo; } \\
\text { redução de embalagens } \\
\text { do produto final; } \\
\text { utilização de material } \\
\text { biodegradável; redução } \\
\text { da quantidade de uso } \\
\text { da terra; sistema de } \\
\text { logística reversa; reúso } \\
\text { de insumos químicos; } \\
\text { utilização de matéria- } \\
\text { prima orgânica }\end{array}$ & $\begin{array}{l}\text { Qualidade da matéria- } \\
\text { prima; economia } \\
\text { gerada com redução } \\
\text { de desperdícios; } \\
\text { valor agregado ao } \\
\text { produto; diversificação } \\
\text { de produtos no } \\
\text { portfólio da empresa; } \\
\text { planejamento } \\
\text { estratégico e financeiro } \\
\text { do produto; balanço } \\
\text { econômico/financeiro; } \\
\text { investimento em } \\
\text { logística reversa; } \\
\text { geração de empregos } \\
\text { nacionais; situação } \\
\text { financeira da empresa } \\
\text { saudável }\end{array}$ & $\begin{array}{l}\text { Melhoria da } \\
\text { ergonomia; redução } \\
\text { de exposição a } \\
\text { produtos químicos; } \\
\text { melhoria da qualidade } \\
\text { no entorno; geração } \\
\text { de emprego e renda; } \\
\text { utilização de mão de } \\
\text { obra local; benefícios } \\
\text { para o colaborador; } \\
\text { zero mão de obra } \\
\text { escrava e infantil; } \\
\text { direito a associações } \\
\text { livres do trabalhador; } \\
\text { inclusão social, racial } \\
\text { e de gênero; sistemas } \\
\text { de reclamação } \\
\text { interno e externo; } \\
\text { promoção das justiças } \\
\text { trabalhistas; ações } \\
\text { contra corrupção e } \\
\text { suborno; ações na } \\
\text { melhoria da qualidade } \\
\text { do ambiente de } \\
\text { trabalho; redução de } \\
\text { exposição à toxicidade }\end{array}$ & $\begin{array}{l}\text { Investimento em } \\
\text { pesquisa aplicada; } \\
\text { ações para a } \\
\text { gestão da inovação } \\
\text { tecnológica; tecnologia } \\
\text { agregada no produto; } \\
\text { rastreabilidade } \\
\text { do produto; } \\
\text { estabelecimento de } \\
\text { parcerias internacionais } \\
\text { para transferência de } \\
\text { tecnologia }\end{array}$ \\
\hline
\end{tabular}


tar que é preciso ainda definir os indicadores e as métricas para os requisitos listados, além de verificar suas interdependências e aqueles que já são preconizados na literatura.

A pesquisa colabora ainda com informações importantes e relevantes que poderão subsidiar a $\mathrm{CNI}$ e a ABIT nas discussões sobre compras governamentais. Pode auxiliar o setor a caminhar em busca da sustentabilidade de seus produtos e processos, utilizando os resultados como referência.

O trabalho mostrou o potencial da aplicação da técnica de mapeamento cognitivo na definição de requisitos e no processo de estruturação de problemas de natureza complexa. $O$ resultado obtido pode servir como base estruturada para decisões de priorização de temas e formas de atuação do setor produtivo.

Esta pesquisa, por conta das limitações de tempo e de acesso à informação, pretendeu gerar uma lista de requisitos de sustentabilidade na visão de especialistas do setor industrial têxtil e de confecção que servisse de subsídio para o debate em fóruns governamentais e que auxiliasse o setor na incorporação dessa temática no processo de desenvolvimento de seus produtos e processos. Não foram recomendados indicadores e métricas associados a cada um dos requisitos listados. Além disso, não foi possível realizar a comparação entre estes e os preconizados na literatura. Por fim, não foi possível verificar a relação existente entre os requisitos listados, a fim de identificar a existência de correlação entre eles, pois se entende que devem ser independentes.

Sugerem-se pesquisas que possam verificar se os requisitos levantados por este trabalho vão ao encontro dos preconizados na literatura e ainda estudos para identificar a independência entre os requisitos, além de estabelecer indicadores e métricas para cada requisito identificado, considerando as métricas já existentes, em níveis nacional e internacional, mas sendo particularizadas para o setor têxtil e de confecção.

\section{REFERÊNCIAS}

AZEVEDO, P. S. de; NOLASCO, A. M. Fatores de incorporação de requisitos ambientais no processo de desenvolvimento de produtos em indústrias de móveis sob encomenda. Ciência Rural, v. 39, n. 8, p. 2422-2427, 2009. http://dx.doi. org/10.1590/S0103-84782009000800023

BORK, C. A. S. Método para avaliação da sustentabilidade de produtos e processos em sistemas produtivos: uma aplicação para escolha de fluidos de corte. São José dos Campos: ITA, 2015.

BORK, C. A. S.; SOUZA, J. F.; GOMES, J. O.; CANHETE, V. V. P.; DE BARBA JR., D. J. Methodological tools for assessing the sustainability index (SI) of industrial production processes. The International Journal of Advanced Manufacturing Technology, v. 87, n. 5-8, p. 1313-1325, 2016. http://dx.doi.org/10.1007/s00170-014-6684-8

BRASIL. Conselho Superior da Justiça do Trabalho. Guia de contratações sustentáveis da justiça do trabalho. 2. ed. Brasília: Conselho Superior da Justiça do Trabalho, 2014.

. Ministério do Meio Ambiente. Portaria n. 61, de 15 de maio de 2008. Diário Oficial da União, p. 93-94, 2008.

CARDOSO, J. R. Contratações públicas sustentáveis: da teoria à prática. Brasília: ENAP, 2016.

CAVALCANTI, D.; OLIVEIRA, G.; D’AVIGNON, A.; SCHNEIDER, H.; TABOULCHANAS, K. Compras Públicas Sustentáveis: diagnóstico, análise comparada e recomendações para o aperfeiçoamento do modelo brasileiro. Santiago: Comissão Econômica para a América Latina e o Caribe (CEPAL), 2017.

CENTENERA, J.; HASAN, M. Sustainable Product-Service Systems. International Business Research, v. 7, n. 7, p. 62-71, 2014. http://dx.doi.org/10.5539/ibr.v7n7p62 
CRUZ, M. H. Utilização de uma metodologia de apoio à decisão na análise de outsourcing em uma empresa metalúrgica. Campinas: UNICAMP, 2011.

DE BARBA JR., D. J. Framework para a avaliação da sustentabilidade de produtos manufaturados. São José dos Campos: ITA, 2015.

DEMAJOROVIC, J.; MATURANA, L. M. Desenvolvimento de produtos sustentáveis: purificadores de água brastemp e carpetes interface. Revista de Gestão Social e Ambiental, v. 3, n. 3, p. 102-119, 2009. http://dx.doi.org/10.24857/ rgsa.v3i3.179

DIEGEL, O.; SINGAMNENI, S.; REAY, S.; WITHELL, A. Tools for Sustainable Product Design: Additive Manufacturing. Journal of Sustainable Development, v. 3, n. 3, p. 68-75, 2010. https://doi.org/10.5539/jsd.v3n3p68

EDLER, J.; GEORGHIOU, L. Public procurement and innovation-Resurrecting the demand side. Research Policy, v. 36, n. 7, p. 949-963, 2007. https://doi.org/10.1016/j.respol.2007.03.003

ELKINGTON, J. Cannibals with forks: The triple bottom line of sustainability. Gabriola Island: New Society Publishers, 1998.

ELLRAM, L. M.; TATE, W.; CARTER, C. R. Applying 3DCE to environmentally responsible manufacturing practices. Journal of Cleaner Production, v. 16, n. 15, p. 1620-1631, out. 2008.

ENSSLIN, L.; MONTIBELLER, G. N.; NORONHA, S. M. D. Apoio à decisão: metodologias para estruturação de problemas e avaliação multicritério de alternativas. Florianópolis: Insular, 2001.

FISHER, E. The Power of Purchase: Addressing Sustainability through Public Procurement. European Procurement \& Public Private Partnership Law Review, v. 8, n. 1, p. 2-7, 2013. https://doi.org/10.21552/EPPPL/2013/1/157

GELDERMAN, C. J.; SEMEIJN, J.; BOUMA, F. Implementing sustainability in public procurement: the limited role of procurement managers and party-political executives. Journal of Public Procurement, v. 15, n. 1, p. 66-92, 2015. https:// doi.org/10.1108/JOPP-15-01-2015-B003

GOVERNOS LOCAIS PELA SUSTENTABILIDADE SECRETARIADO PARA AMÉRICA LATINA E CARIBE (GLSSALC). Guia de compras públicas sustentáveis. 2. ed. ICLEI (LACS), 2008.

GMELIN, H.; SEURING, S. Determinants of a sustainable new product development. Journal of Cleaner Production, v. 69, p. 1-9, 2014. https://doi.org/10.1016/j.jclepro.2014.01.053

GOMES, L. F. A. M.; GOMES, C. F. S.; ALMEIDA, A. T. de. Tomada de decisão gerencial enfoque multicritério. São Paulo: Atlas, 2009. $324 \mathrm{p}$.

INSTITUTO BRASILEIRO DE GEOGRAFIA E ESTATÍSTICA. Participação da despesa de consumo das administrações públicas em relação ao produto interno bruto. In: Séries históricas e estatísticas. Disponível em: <https://seriesestatisticas. ibge.gov.br/series.aspx?no=12\&op=0\&vcodigo=SCN34\&t=participacaodespesa-consumo-administracoes-publicasbrem>. Acesso em: 28 jun. 2015.

LAI, K.; WONG, C. W. Y. Green logistics management and performance: Some empirical evidence from Chinese manufacturing exporters. Omega, v. 40, n. 3, p. 267-282, 2012. https://doi.org/10.1016/j.omega.2011.07.002

LIMA, A. S. de. Proposta de método para modelagem de critérios de priorização de projetos de pesquisa e desenvolvimento aeroespaciais. São José dos Campos: ITA, 2008.

MARX, Â. M.; PAULA, I. C. de. Proposta de uma sistemática de gestão de requisitos para o processo de desenvolvimento de produtos sustentáveis. Produção, v. 21, n. 3, p. 417-431, 2011. https://doi.org/10.1590/S0103-65132011005000041 
MEDEIROS, J. F. de; RIBEIRO, J. L. D.; CORTIMIGLIA, M. N. Success factors for environmentally sustainable product innovation: A systematic literature review. Journal of Cleaner Production, v. 65, p. 76-86, 2014. http://dx.doi. org/10.1016/j.jclepro.2013.08.035

MUSANGO, J. K.; BRENT, A. C. A conceptual framework for energy technology sustainability assessment. Energy for Sustainable Development, v. 15, n. 1, p. 84-91, 2011. https://doi.org/10.1016/j.esd.2010.10.005

RAYMOND, J. Benchmarking in public procurement. Benchmarking: An International Journal, v. 15, n. 6, p. 782-793, 2008. https://doi.org/10.1108/14635770810915940

THAI, K. V. Public Procurement Re-examined. Journal of Public Procurement, v. 1, n. 1, p. 9-50, 2001. https://doi. org/10.1108/JOPP-01-01-2001-B001

TOLENTINO, L. Governo e indústria procuram medidas de apoio à produção e consumo sustentáveis. Brasil: Ministério do Meio Ambiente, 2013. Disponível em: <http://www.mma.gov.br/informma/item/9685-governo-e-ind\%C3\%BAstriaprocuram-medidas-de-apoio-\%C3\%A0-economia-verde>. Acesso em: 7 maio 2015.

UNITED NATIONS ENVIRONMENT PROGRAMME (UNEP). Life cycle management. A businees guide to sustainability. Nairobi: UNEP, 2007.

UTTAM, K.; LE LANN ROOS, C. Competitive dialogue procedure for sustainable public procurement. Journal of Cleaner Production, v. 86, p. 403-416, 2015. https://doi.org/10.1016/j.jclepro.2014.08.031

VAN WEENEN, J. C. Towards sustainable product development. Journal of Cleaner Production, v. 3, n. 1-2, p. 95-100, 1995. https://doi.org/10.1016/0959-6526(95)00062-J

WORLD COMMISSION ON ENVIRONMENT AND DEVELOPMENT (WCED). Report of the World Commission on Environment and Development: Our Common Future (The Brundtland Report). Genebra: WCED, 1987. Disponível em: <http://www.un-documents.net/wced-ocf.htm>. Acesso em: 4 mar. 2015.

ZHU, Q.; SARKIS, J.; LAI, K. Green supply chain management: pressures, practices and performance within the Chinese automobile industry. Journal of Cleaner Production, v. 15, n. 11-12, p. 1041-1052, 2007. https://doi.org/10.1016/j. jclepro.2006.05.021 